\title{
Smart Grid Law and Regulation-Case Study of Tafila Smart Grid
}

\author{
Mohammad Mahasneh", Qais Alsafasfeh ${ }^{2}$ \\ ${ }^{1}$ Faculty of Administrative \& Financial Sciences, Tafila Technical University, Tafila, Jordan \\ ${ }^{2}$ Electrical Engineering Department, Tafila Technical University, Tafila, Jordan \\ Email: qshashim@ttu.edu.jo
}

Received 2 December 2013; revised 3 January 2014; accepted 2 February 2014

Copyright (C) 2014 by authors and Scientific Research Publishing Inc.

This work is licensed under the Creative Commons Attribution International License (CC BY). http://creativecommons.org/licenses/by/4.0/

(c) (i) Open Access

\begin{abstract}
Creation of a Smart Grid provides utilities and their customers with a significant improvement in power reliability and services; to date, Smart Grid in Jordan is still in infant stage. In this paper we will present the Smart grid policy and law in Jordan by studying Tafila smart grid as a case study. One can see variety of problems and challenges in the field of Smart Grid. Hence, this paper can provide a help to find a new research point in this field. Also in this paper we try to recommend develop implementation strategy that will help to generate appropriate smart grid \& Energy Efficiency Law.
\end{abstract}

Keywords

Smart Grid; Renewable Energy; Legislative; Regulatory

\section{Introduction}

Integration of smart grid provides multiple advantages concerning operation security, integration of renewable energy as well as energy trading but bulk smart grid may encounter major blackouts, which originate in increasing complication in monitoring, operation and control of interconnected power grids. Energy production in general, and electric energy in particular are ever increasing in cost, and with the decrease in fossil fuels world reserve and the increase in the world energy demand, the price per KWh will only get more expensive to produce and hence to consume. Like most countries in the world, Jordan has seen a steady increase in its energy demand (6\% to 8\%) since 1998 (Al zou’bi, 2010; Etier, Al Tarabsheh, \& Ababneh, 2010; Hrayshat \& Al-Soud, 2007), in addition to keeping up with the increased energy demand, Jordan faces the challenge of reducing its dependence on foreign energy supply (current dependence on foreign energy resources is estimated at $98 \%$ ).

To tackle the issues mentioned above, Jordan has adopted a strategic decision to add renewable energy based 
capacity. Although the Jordan government took a good step in increasing its renewable energy electricity production, the Jordan population needs to take steps into integrating its own share of renewable capacity and help resolve the aforementioned issues. The huge increase in distributed generation (DG) will introduce new challenges to the national dispatcher.

Currently, the dispatcher manages a centralized generation with a known installed capacity and load behavior. With the presence of a significant DG capacity, the balance might not be maintained and the characterization of the residential profiles in the presence of renewable generation remains imperative for the proper management of the national grid (Al-Soud \& Hrayshat, 2009).

\section{Tafila Smart Grid Overview}

A "smart grid" provides electricity suppliers and consumers the ability to use digital technology to control devices in consumers' homes to save energy, reduce costs and increase reliability and transparency in service. The Smart meters may be part of a smart grid, but alone do not constitute a smart grid (Nalbalwar, Ruikar, \& Sakpal, 2012). A smart grid includes an intelligent monitoring system that keeps track of all electricity flowing in the system. Also incorporates the use of transmission lines with lower energy losses and the integration ability of alternative sources of electricity, such as solar and wind (Kim, 2011).

Tafila Distributed Smart Grid focus is to pull our nation away from relying on traditional, non-renewable energy sources while encouraging the use of solar energy sources. This grid will be the first in Jordan to deploy smart solar technology—highly distributed solar energy generation coupled with smart grid technology-for every electric utility subscriber throughout an entire region in this system a Smart solar systems will be installed on 20,000 solar panel rooftops in the Governorate of Tafila as shown in Figure 1, this project leading with Petra Solar from/USA. This system includes an intelligent monitoring system that keeps track of all electricity flowing in the system as shown Figures 2(a)-(c), the monitoring system will help to monitor voltage, load, current at each customer including in smart grid.

\section{The History of Jordan Smart Grid Policy}

The government has also established a new Energy Fund to support the infrastructure development of new renewable energy facilities. In addition the government is seeking to provide tax incentives to remove the barriers for the comprehensive use of energy efficiency and renewable energy technologies in the Jordanian market (Zafar, 2011).

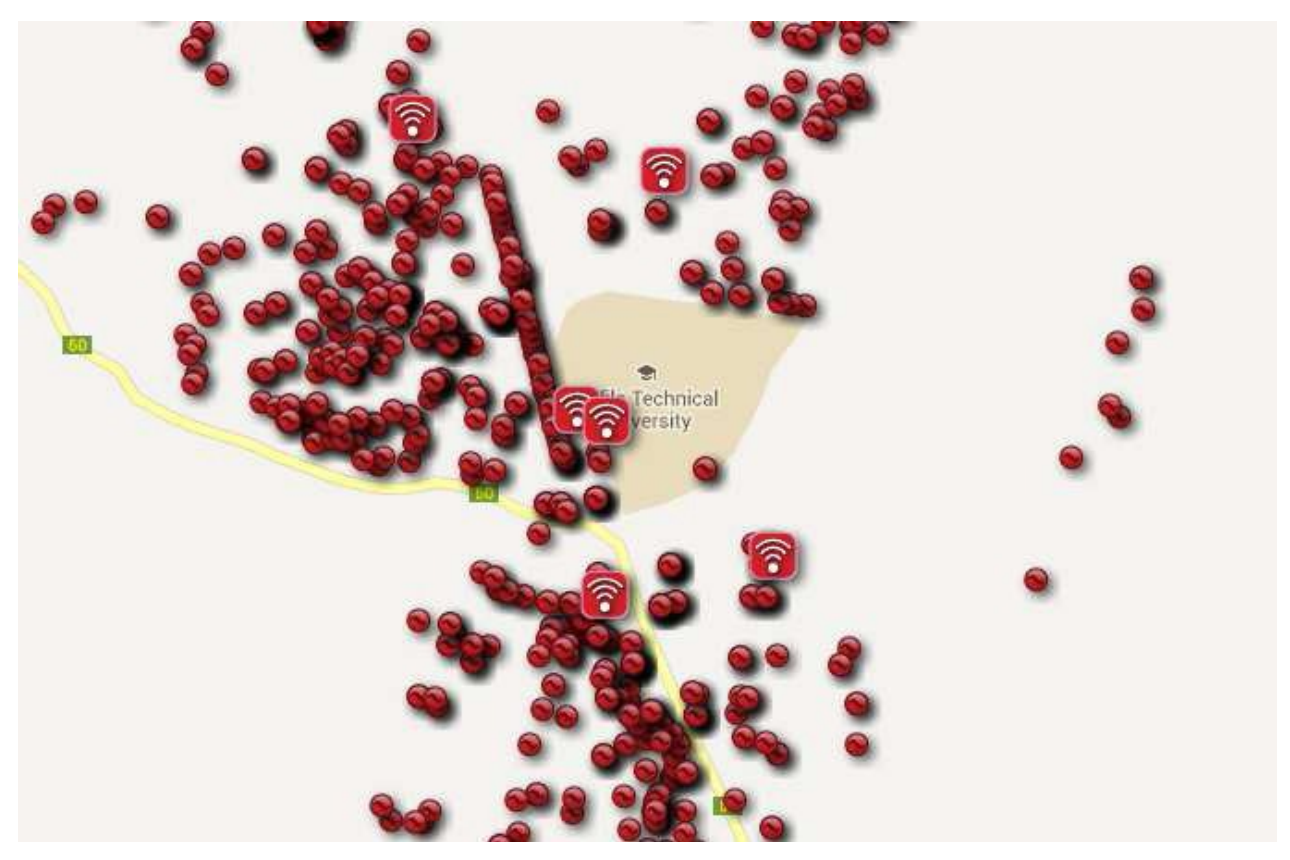

Figure 1. Tafila smart grid location in Governorate of Tafila. 


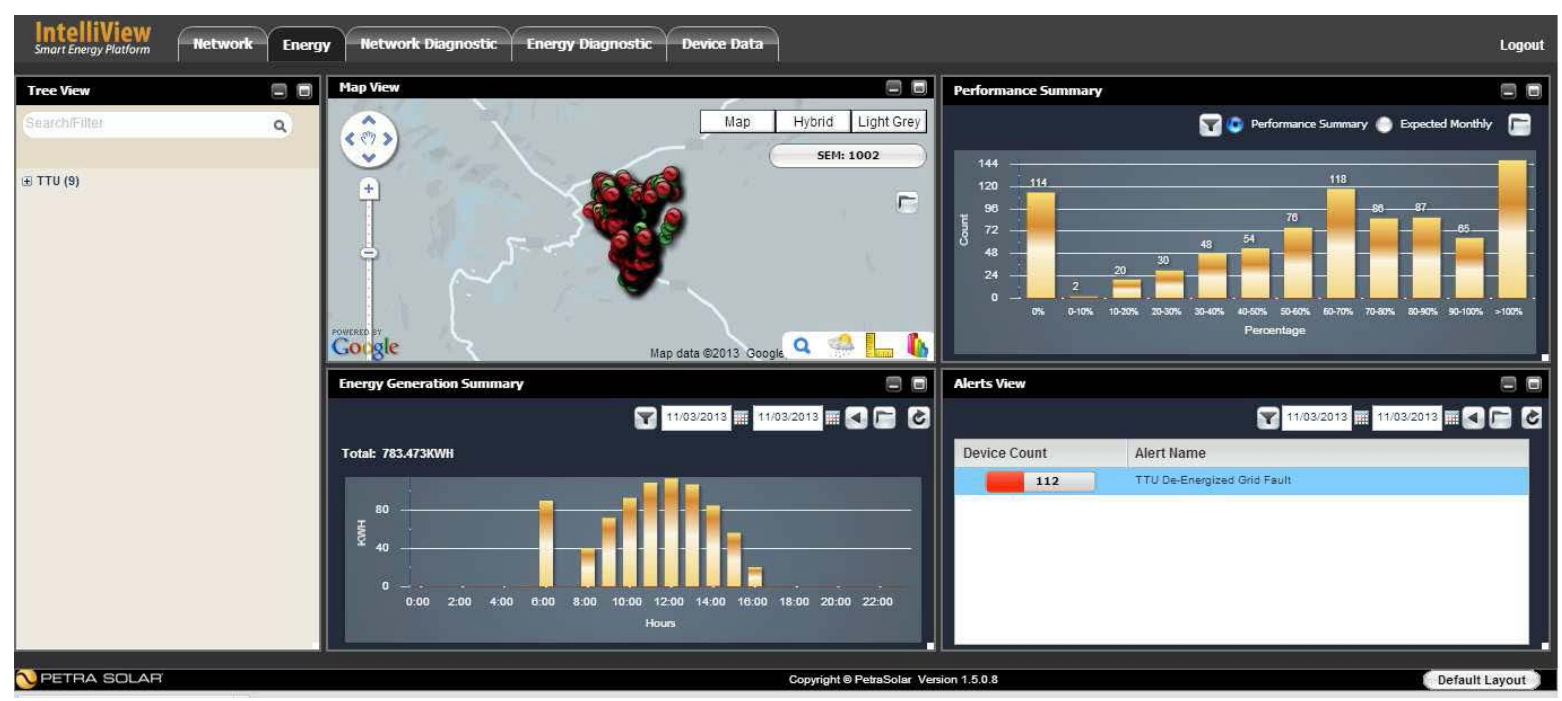

(a)

จ $11 / 03 / 2013$ 通 $11 / 03 / 2013$ 通 4 厂 C

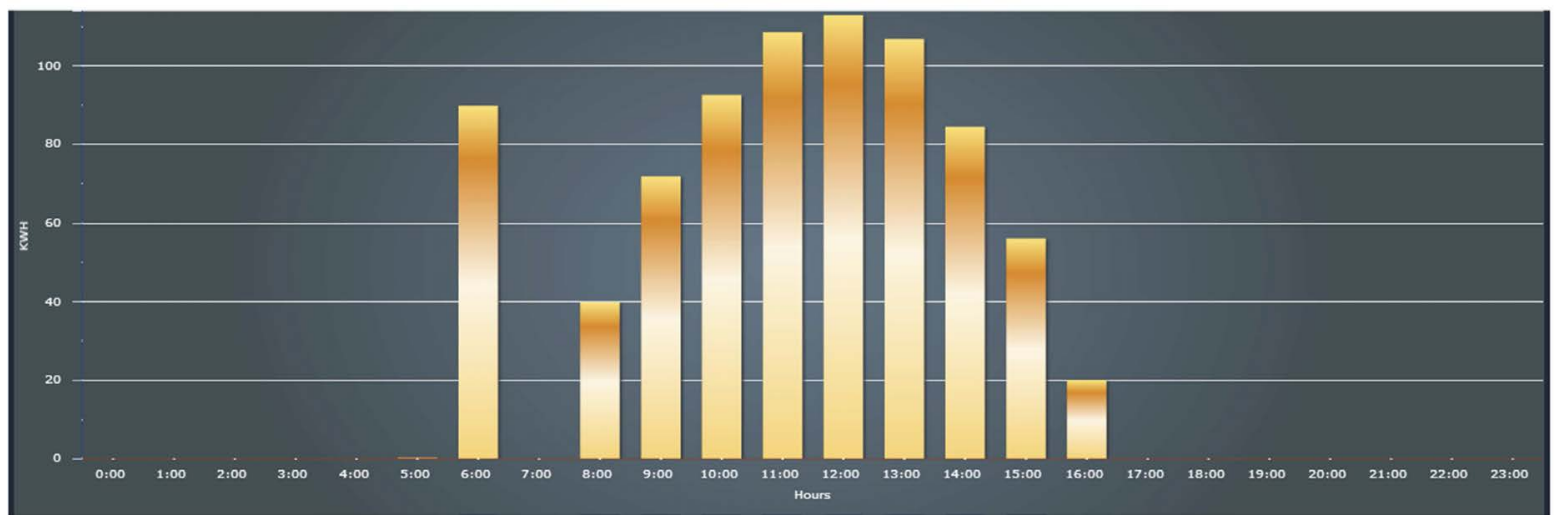

(b)

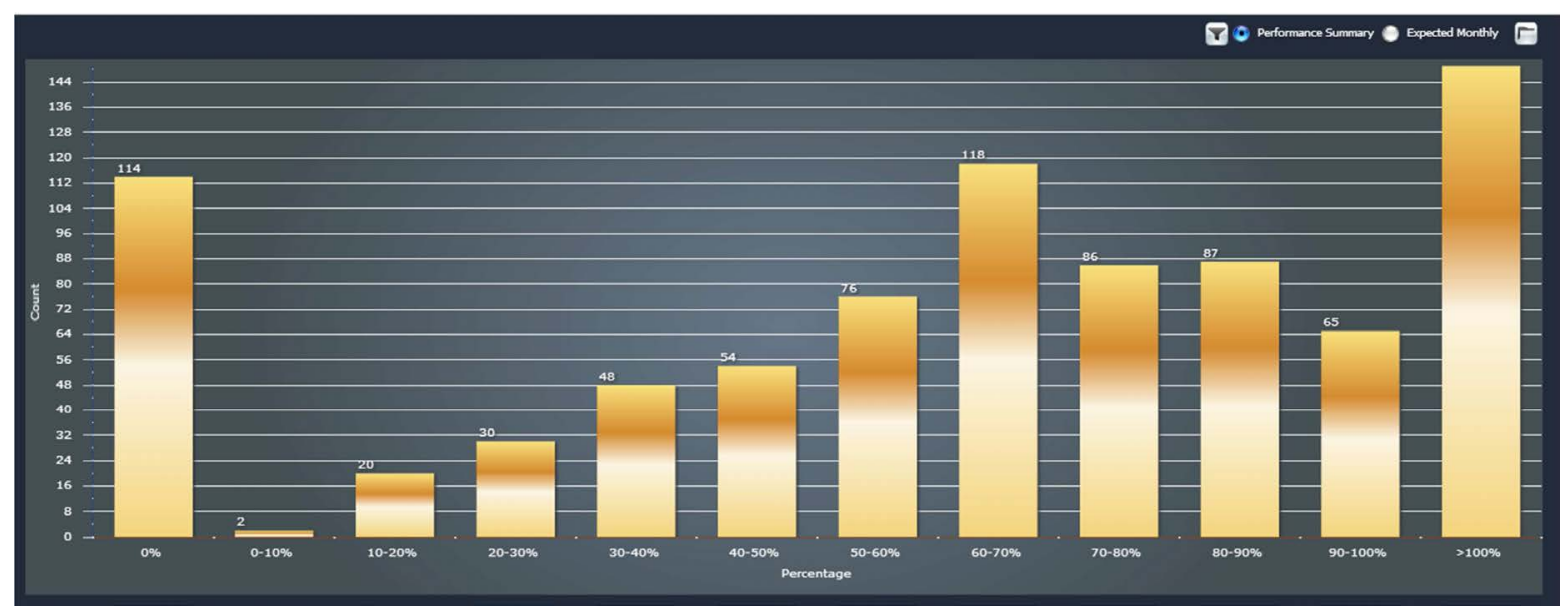

(c)

Figure 2. Smart grid intelligent monitoring system.

In March 2010, the government of Jordan issued the law of renewable energy and energy efficiency which will allow to the private sector to invest in this field. According to this law, the tariff of electricity which is pro- 
duced from renewable energy resources should be fixed and acceptable within reference scale (Al-Salaymeh, 2012).

Based on 2010 law, new law was issued to organize the working policy in Renewable Energy is Law No. (13) Of 2012 Renewable Energy \& Energy Efficiency Law, This Law shall be called (Renewable Energy \& Energy Efficiency Law, 2012). Both of laws are not mention the smart grid explicitly and how we can deal with any issue regarding smart grid (MEMR, 2013).

The Smart Grid will span the globe, and the United States is not alone in its initiative to modernize the electric grid. A number of other countries have launched significant efforts to encourage the development of the Smart Grid in their own countries and regions.

\section{Smart Grid Legislative and Regulatory Recommendations}

In consideration of the information in this paper, Development of systems and recommend legislation aimed at optimizing the use of smart grid, the following recommendations are made to assist stakeholders as they make smart grid technology deployment decisions and also develop implementation strategy:

- Demand side management

- Demand response

- Energy efficiency projects

- Advanced/smart metering

- Net metering

- Distributed and intermittent generation interconnection

- Dynamic pricing

1) The customer price signals should reflect the real-time cost at the time of actual energy use. Public incentives must be neutralized by the choices of resource demand and supply by linking benefits to energy services provided, not just sales kWh.

2) Investments in smart grid before the meter be recovered as fixed costs. The cost of the meters and load control equipment specific customer's load control must be retrieved from a variable as variable cost or as part of an energy charge.

3) The risks associated with the deployment of smart grid assets must be symmetrically allocated to those best placed to manage the assets and with more at stake financially have the greatest potential for gain or loss.

4) All customer-specific data must belong to customers for use as he determines. The aggregate data system should be considered public information.

5) Smart meters should be installed on a universal basis in order to capture their optimal benefits.

6) Crucial national standards, and is particularly important for subway systems and data capable of bidirectional communication with customers, suppliers and can move between providers.

7) Crucial national standards, and is particularly important for subway systems and data capable of bidirectional communication with customers, suppliers and can move between providers.

8) Customers must have a specifically counted set of rights, including (but not limited to) the right to:

- Confidentiality of personal information;

- Ownership of information;

- Choice of supplier and/or portfolio of supply options;

- Real-time price information;

- Appliance control;

- Install equipment to improve service quality;

- Net metering;

- Subscribe to aggregation of demand;

- Select meter and post-meter devices;

- Avoid asymmetric allocation of risk and reward; and

- Choose level of service quality.

9) Must be evaluated new smart grid products and programs to identify best and worst practices and reduce losses of consumers when there is something wrong.

10) Utilities should have the right incentives to earnings to final execution and value to customers, instead of kilowatt-hour sales. These incentives also encourage public services to innovate (U.S. Energy Information Administration (EIA), 2011; Brown \& Salter, 2010). 


\section{Conclusion}

There has been significant progress in the implementation of clean energy systems in Jordan, with active support from the government and increasing awareness among the local population. In this paper we try to recommend develop implementation strategy that will help to generate appropriate smart grid \& Energy Efficiency Law; these recommendations will play main stone in future law in smart grid.

\section{References}

Al zou'bi, M. (2010). Renewable Energy Potential and Characteristics in Jordan. Jordan Journal of Mechanical and Industrial Engineering, 4, 45-48.

Al-Salaymeh, A. (2012). Act of Feed-In-Tarif Law in Promoting the Utilization of Renewable Energy in Jordan.

Al-Soud, M. S., \& Hrayshat, E. S. (2009). Rural Photovoltaic Electrification Program in Jordan. Renewable and Sustainable Energy Reviews, 8, 593-598.

Brown, A., \& Salter, R. (2010). Smart Grid Issues in State Law and Regulation. Palo Alto, CA: Galvin Electricity Initiative.

Etier, I., Al Tarabsheh, A., \& Ababneh, M. (2010). Analysis of Solar Radiation in Jordan. Jordan Journal of Mechanical and Industrial Engineering, 4, 733-738.

Hrayshat, E. S., \& Al-Soud, M. S. (2007). Potential of Solar Energy Development for Water Pumping in Jordan. Renewable Energy, 29, 1393-1399.

Kim, T.-H. (2011). Securing Communication of SCADA Components in Smart Grid Environment. International Journal of Systems Applications, Engineering \& Development, 2, 135-142.

Law No. (13) of 2012: Renewable Energy \& Energy Efficiency Law. (2012). http://www.memr.gov.jo/LinkClick.aspx?fileticket=vblQv7AybK8\%3D\&tabid=253

Nalbalwar, S. L., Ruikar, J. D., \& Sakpal, S. R. (2012). Smart Grid: A Modernization of Existing Power Grid. International Journal of Advanced Engineering Research and Studies, 1, 295-298.

U.S. Energy Information Administration (EIA) (2011). Smart Grid Legislative and Regulatory Policies and Case Studies, U.S. State Legislative and Regulatory Policies.

Zafar, S. (2011). Renewable Energy in Jordan. http://www.ecomena.org/tag/renewable- energy-law/ 